\title{
Waist Circumference, Waist Hip Ratio and Body Mass Index in Female Undergraduates of a Tertiary Institution in Nigeria: a Cross-sectional Study
}

\author{
Adamu A. Rufa'i \\ University of Maiduguri, adamuarufai@unimaid.edu.ng \\ Karimah I. Sajoh \\ Bayero University Kano, karimahsajoh@yahoo.com \\ Adewale L. Oyeyemi \\ University of Maiduguri, alaoyeyemi@yahoo.com \\ Abdullahi S. Gwani \\ Abubakar Tafawa Balewa University, Bauchi, asgwani@yahoo.com
}

Follow this and additional works at: https://nsuworks.nova.edu/ijahsp

Part of the Medicine and Health Sciences Commons

\begin{abstract}
Recommended Citation
Rufa'i AA, Sajoh KI, Oyeyemi AL, Gwani AS. Waist Circumference, Waist Hip Ratio and Body Mass Index in Female Undergraduates of a Tertiary Institution in Nigeria: a Cross-sectional Study. The Internet Journal of Allied Health Sciences and Practice. 2019 Jan 01;17(1), Article 12.
\end{abstract}

This Manuscript is brought to you for free and open access by the College of Health Care Sciences at NSUWorks. It has been accepted for inclusion in Internet Journal of Allied Health Sciences and Practice by an authorized editor of NSUWorks. For more information, please contact nsuworks@nova.edu. 


\title{
Waist Circumference, Waist Hip Ratio and Body Mass Index in Female Undergraduates of a Tertiary Institution in Nigeria: a Cross-sectional Study
}

\begin{abstract}
Purpose: Obesity and overweight are associated with variety of conditions detrimental to health, wellbeing and longevity. Waist circumference and waist to hip ratio are indicators of risk of central adiposity while body mass index is an indicator of overall risk of obesity. Body mass index has been traditionally used as a standard for determining overweight and obesity. This study was designed to determine the relationship between waist circumference, waist to hip ratio and body mass index among female undergraduates of a Nigerian University. Also prevalence of obesity based on waist circumference, waist to hip ratio and body mass index was explored. Methods: Three hundred and sixty four apparently healthy subjects were recruited for the study using a cross-sectional simple random sampling technique. Waist circumference, waist to hip ratio and body mass index were determined using standard methods. Descriptive statistics were used to summarize the physical characteristics of the participants. Pearson correlation coefficient was used to analyze the relationship between waist circumference, waist to hip and body mass index. Results: The mean age, waist circumference, waist to hip ratio and body mass index of the participants were $22.5( \pm 2.20)$ years, $79.36( \pm 10.4) \mathrm{cm}, 0.81( \pm 0.06)$, and $22.48( \pm 4.50) \mathrm{kg} / \mathrm{m}^{2}$ respectively. The prevalence of obesity based on body mass index, waist circumference and waist to hip ratio was found to be $6.3 \%, 17.6 \%$ and $25.5 \%$ respectively. Significant relationship was found between waist circumference and body mass index $(r=0.81 ; p<0.001)$, and between waist to hip ratio and body mass index $(r=0.25$; $p<0.001)$. Conclusions: Body mass index was related to waist circumference, as well as to waist to hip ratio. The prevalence of obesity based on waist to hip ratio was highest among female undergraduates in a Nigerian university. Awareness on the importance of waist to hip ratio as indicator of risk of obesity should be created among female undergraduates in Nigerian Universities and by extension among the women population in general.
\end{abstract}

\section{Author Bio(s)}

Adamu A. Rufa'i, $P h D, M S c, M N S P$, is a Head of Department and a Senior Lecturer in Physiotherapy in the College of Medical Sciences at the University of Maiduguri. He is also an Honorary Physiotherapist at the University of Maiduguri Teaching Hospital.

Karimah I. Sajoh, BMR, MNSP, is a graduate of Physiotherapy from the University of Maiduguri and currently pursuing her Master's program in Neurophysiotherapy at Bayero University Kano. She is a licensed Physiotherapy practitioner in Nigeria.

Adewale L. Oyeyemi, PhD, MSc, MNSP, is a Senior Lecturer in Physiotherapy in the College of Medical Sciences at the University of Maiduguri. He is also the coordinator of Physiotherapy postgraduate program in the College of Medical Sciences, University of Maiduguri.

Abdullahi S. Gwani, MSc, BSc, is a Lecturer in Anatomy in the College of Medical Sciences at the Abubakar Tafawa Balewa University, Bauchi. He is currently pursuing his PhD in Clinical Anatomy at the prestigious Ahmadu Bello University Zaria in Nigeria.

\section{Acknowledgements}

We would like to express our sincere gratitude to all participants for voluntarily taking part in this study. 


\title{
IJAHSP \\ The Internet Journal of Allied Health Sciences and Practice \\ Dedicated to allied health professional practice and education
}

Vol. 17 No. 1 ISSN 1540-580X

\section{Waist Circumference, Waist Hip Ratio, and Body Mass Index in Female Undergraduates of a Tertiary Institution in Nigeria: a Cross Sectional Study}

\author{
Adamu A. Rufa"i 1 \\ Karimah I. Sajoh ${ }^{2}$ \\ Adewale L. Oyeyemi ${ }^{1}$ \\ Abdullahi S. Gwani ${ }^{3}$
}

1. University of Maiduguri

2. Bayero University Kano

3. Abubaker Tafawa Balewa University

Nigeria

\begin{abstract}
Purpose: Obesity and overweight are associated with variety of conditions detrimental to health, wellbeing, and longevity. Waist circumference and waist-to-hip ratio are indicators of risk for central adiposity while body mass index is an indicator of overall risk of obesity. Body mass index has been traditionally used as a standard for determining overweight and obesity. This study was designed to determine the relationship between waist circumference, waist-to-hip ratio, and body mass index among female undergraduates of a Nigerian University. Also prevalence of obesity based on waist circumference, waist-to-hip ratio, and body mass index was explored. Methods: Three hundred and sixty four (364) apparently healthy subjects were recruited for the study using a cross-sectional simple random sampling technique. Waist circumference, waist-to-hip ratio, and body mass index were determined using standard methods. Descriptive statistics were used to summarize the physical characteristics of the participants. A Pearson correlation coefficient was used to analyze the relationship between waist circumference, waist-to-hip ratio, and body mass index. Results: The mean age, waist circumference, waist-to-hip ratio, and body mass index of the participants were 22.5 $( \pm 2.20)$ years, $79.36( \pm 10.4) \mathrm{cm}, 0.81( \pm 0.06)$, and $22.48( \pm 4.50) \mathrm{kg} / \mathrm{m}^{2}$ respectively. The prevalence of obesity based on body mass index, waist circumference, and waist-to-hip ratio was found to be $6.3 \%, 17.6 \%$, and $25.5 \%$ respectively. A significant relationship was found between waist circumference and body mass index $(r=0.81 ; p<0.001)$, and between waist-to-hip ratio and body mass index ( $r=0.25 ; p<0.001)$. Conclusions: Body mass index was related to waist circumference, as well as to waist-tohip ratio. The prevalence of obesity based on waist-to-hip ratio was highest among female undergraduates in a Nigerian university. An awareness of the importance of the waist-to-hip ratio as indicator of risk of obesity should be created among female undergraduates in Nigerian Universities and by extension among the female population in general.
\end{abstract}

Keywords: waist circumference, waist/hip ratio, body mass index, obesity, female undergraduates 


\section{BACKGROUND}

Obesity is one of the leading preventable causes of death that poses serious a public health problem in this century. ${ }^{1}$ It was thought to be a disease of developed nations, but emerging evidence now suggests an alarming and increasing prevalence in the developing nations..$^{2,3} \mathrm{An}$ estimated $20-50 \%$ of the African urban populations are either overweight or obese.,5 In the West African sub region, a prevalence rate of $10 \%$ has been reported, with urban women 3 times likely to be overweight or obese than men. ${ }^{6} \mathrm{~A}$ similar high prevalence has been reported in Nigeria and being overweight or obese is particularly higher among women in northern Nigeria. 2,7

Obesity is the accumulation of excessive fat to the extent of affecting health and general well being that can cause physical and psychological distress. ${ }^{3}$ It is associated with non-communicable diseases and contributes to morbidity and mortality among adults. 3,6,8 Obesity may be evaluated through anthropometric measures such as waist circumference (WC), hip circumference $(\mathrm{HC})$, waist-to-hip ratio $(\mathrm{W} / \mathrm{H})$ and body mass index $(\mathrm{BMI}) .{ }^{9,10} \mathrm{BMI}$ is mostly used as an initial assessment to identify individuals at risk for problems related to being overweight or obese and has been shown as an indicator of overall obesity, while WC and W/H are indicators for abdominal obesity. ${ }^{11}$

Results of previous studies on these anthropometric indicators of obesity and obesity-related problems show many discrepancies. ${ }^{11-22}$ For example, in the Netherlands, a study concluded that WC predicts overweight much more than BMI, suggesting it could replace $\mathrm{BMI}$ and $\mathrm{W} / \mathrm{H}$ as an indicator for weight management. ${ }^{13,19} \mathrm{~A}$ study among aboriginal people of Australia indicates that WC, BMI, and hip circumference $(\mathrm{HC})$ are associated with cardiovascular outcomes, but WC is a better correlate of visceral fat and a predictor of cardiovascular disease (CVD) risk than the WHR. ${ }^{20}$ However, another study, found that both WC and $\mathrm{W} / \mathrm{H}$ predict abdominal obesity as indicator of risk of CVD. ${ }^{17}$

Available literature on the relationship of the anthropometric measures such as WC, WHR, and BMI with obesity and its related complications are mostly conducted in different populations in the developed countries. The few available ones from the developing countries concentrated on the comparison between men and women., 5,23 Moreover, there has been argument regarding the use of $\mathrm{BMI}$, hence, other indicators are required in order to compliment the BMI measurement used mostly to identify those at risk of obesity-related morbidity because of abdominal fat accumulation. ${ }^{3,22}$

There is scarcity of documented information about anthropometric indicators of obesity among female university students in Nigeria. Understanding simple and easy to use anthropometric measures that can best predict the risk of becoming overweight or obese among female university students could be useful in the prevention and control of the increasing prevalence of chronic diseases occurring in Nigeria. The objective of this study was to determine the relationships between outcomes from BMI and WC, and W/H. As a secondary objective, the prevalence of obesity using the 3 measures of adiposity including WC, W/H and BMI were explored.

\section{Methods \\ Research Design, Setting, and Study Population}

The research design was a cross sectional survey. The setting was female students' hostels of University of Maiduguri, Maiduguri, Nigeria. Female undergraduate students of University of Maiduguri, Maiduguri, Nigeria were the study population.

\section{Sample Size}

The sample size was determined statistically using the Taro Yamane formula for a finite population: $n=N / 1+N(e)^{2}$; where $n=$ sample size, $\mathrm{N}=$ finite population, $\mathrm{e}=$ level of significance (also termed limit of tolerable error), and $1=$ constant.

Given $\mathrm{N}=3032$, e $=5.0 \%(0.05)$. A total of 389 participants were required considering $10 \%$ attrition rate. However, 364 participants responded accounting for $93.6 \%$ response rate.

\section{Sampling Technique}

Simple random sampling technique was employed to recruit participants who were contacted in the hostel in their rooms, after the purpose and benefits of the study was explained to them.

\section{Study Instruments}

The instruments for this study included a calibrated wooden height meter used to measure the participants' height to the nearest $0.1 \mathrm{~cm}$. A weighing scale (Hanson, China) was used to measure the participants' weight to the nearest $0.1 \mathrm{~kg}$, and an inelastic tape rule (Butterfly Shanghai, China) was used to measure waist and hip circumferences to the nearest $0.1 \mathrm{~cm}$. Prior to use, the weighing scale was calibrated and was also re-checked between subjects. 


\section{Ethical Issues}

The ethical approval of the study was granted by the ethics committee of the University of Maiduguri Teaching Hospital. The participants were contacted individually in their hostel rooms where they were briefed about the purpose, benefits, and the potential risks of the study. The participants were assured that all information obtained for the study would remain confidential and would only be used for research purpose. The procedure of the study was explained to the participants, and those who were voluntarily willing to participate gave signed informed consent prior to the commencement of the study.

\section{Participant Consent}

Participants were randomly sampled from the list of all female students living on campus. The list was obtained from the hostel administration office of the University. Each participant was contacted individually in their halls of residence for recruitment. The purpose and benefits of the study was explained to them; they were also informed that all information obtained from the study would remain confidential and would be treated with honesty.

\section{Data Collection}

All measurements were conducted by a single research staff and performed in the participants' hall of residence on campus. The measurements were made based on standard guidelines. ${ }^{24}$ Weight was measured with the participants wearing light clothing and without external materials that may increase weight, and the reading was recorded to the nearest $0.1 \mathrm{~kg}$. Height was measured with the subject in standing position and back against the wooden height meter without shoes and the measurement was recorded to the nearest $0.1 \mathrm{~cm}$. Measurements were taken twice, and if there were differences, a third measurement was taken and an average of the closest 2 was used for data analysis. For a majority of participants, the first two measurements were very similar, suggesting a good evidence of intra-rater reliability for all measurements. BMI was calculated by dividing the weight in $\mathrm{kg}$ by the square of height in meter $\left(\mathrm{kg} / \mathrm{m}^{2}\right)$, and participants were considered to be obese when they have $B M I \geq 30 \mathrm{~kg} / \mathrm{m}^{2} .3$ Obesity was further classified into class one $\left(30-34.9 \mathrm{~kg} / \mathrm{m}^{2}\right.$, mild obesity), class two $\left(35-39.9 \mathrm{~kg} / \mathrm{m}^{2}\right.$, moderate obesity), and class three $\left(\geq 40 \mathrm{~kg} / \mathrm{m}^{2}\right.$, severe obesity). ${ }^{3} \mathrm{WC}$ was taken at the point midway between the costal margin and iliac crest in the mid-axillary line with the subject standing and breathing normally, and the measurement was recorded to the nearest $0.1 \mathrm{~cm}$. A WC greater than $88 \mathrm{~cm}$ was an indication of abdominal obesity among the participants. $\mathrm{HC}$ was measured at the widest point around the greater trochanter with the subject standing, and the measurement was recorded to the nearest $0.1 \mathrm{~cm}$. W/H was calculated by dividing the waist measurement by the hip measurement, all in centimeters, and W/H more than 0.80 was an indication of increased health risk among participants.

\section{Statistical Analysis}

The data were double checked and cleaned to ensure that the entire variables were properly documented and to detect any missing or erroneous value during data entry. Descriptive statistics of mean and standard deviation were used to describe the physical characteristics (age, weight, height, BMI, WC, HC, W/H). Also, frequency and percentage were used to describe the prevalence of obesity as assessed by WC, W/H, and BMI of the participants. A Pearson correlation coefficient was used to determine the relationship between $\mathrm{WC}$ and $\mathrm{BMI}$ and between $\mathrm{W} / \mathrm{H}$ and $\mathrm{BMI}$ among female undergraduates. Statistical package for Social Sciences (SPSS version 20.0.1) was used for the data entry and analyses. Statistical significance was set at $p=0.05$.

\section{RESULTS}

A total of 364 female undergraduate students participated in the study. Their mean age, weight, and height were $22.51 \pm 2.20$ years, $58.86 \pm 12.11 \mathrm{~kg}$ and $1.62 \pm 0.07 \mathrm{~m}$ respectively. The detailed physical characteristics of the participants are presented in Table 1 .

Table 1: Physical characteristics of the participants $(n=364)$

\begin{tabular}{ccc}
\hline Variables & Mean & SD \\
\hline Age $($ years $)$ & 22.51 & 2.20 \\
Weight $(\mathrm{kg})$ & 58.86 & 12.11 \\
Height $(\mathrm{m})$ & 1.62 & 0.07 \\
BMI $\left(\mathrm{kg} / \mathrm{m}^{2}\right)$ & 22.48 & 4.50 \\
WC $(\mathrm{cm})$ & 79.36 & 10.04 \\
HC $(\mathrm{cm})$ & 97.15 & 9.59 \\
W/H & 0.81 & 0.06 \\
\hline
\end{tabular}

$\mathrm{BMI}=$ body mass index; $\mathrm{WC}=$ waist circumference; $\mathrm{HC}=$ hip circumference; $\mathrm{W} / \mathrm{H}=$ waist-to-hip ratio 
Table 2 shows the prevalence of obesity among the participants. Twenty three participants $(6.3 \%)$ were obese based on the BMI measurements. Waist circumference shows that $17.6 \%$ of the participants were obese while waist hip ratio recorded the highest (25.5\%) number of participants who are obese.

Table 2: Prevalence of obesity based on anthropometric measurements $(n=364)$

\begin{tabular}{lccccc}
\hline Variables & $\mathbf{n}$ & Obese & \multicolumn{3}{c}{ Non-obese } \\
& & $\%$ & $\mathbf{N}$ & $\%$ \\
\hline BMl & 23 & & 6.3 & 341 & 93.6 \\
WC & 64 & & 17.6 & 300 & 82.4 \\
W/H & 73 & & 25.5 & 271 & 74.5 \\
\hline
\end{tabular}

$\mathrm{n}=$ frequency; $\%=$ percentage; $\mathrm{BMI}=$ body mass index; $\mathrm{WC}=$ waist circumference; $\mathrm{W} / \mathrm{H}=$ waist-to-hip ratio

In Table 3, the relationship between WC and BMI was shown to be positive and significant $(r=0.81 ; p<0.001)$. Also there is significantly positive relationship between $\mathrm{W} / \mathrm{H}$ and $\mathrm{BMI}(\mathrm{r}=0.25 ; \mathrm{p}<0.001)$.

Table 3: Relationship between WC, W/H, and BMI

\begin{tabular}{llll}
\hline Variables & Mean $($ SD) & BMl & p-value \\
& $79.4( \pm 10.0)$ & 0.81 & $<0.001$ \\
WC & $0.81( \pm 0.60)$ & 0.25 & $<0.001$ \\
W/H & WC= waist circumference; $W / H=$ waist-to-hip ratio
\end{tabular}

\section{DISCUSSION}

Obesity is a matter of great concern, especially in women, for its vulnerability to various chronic conditions such as diabetes, hypertension, hyperlipidemia , and cardiovascular diseases with attendant morbidity. This study determined the relationship between WC, W/H and BMI as indicators of obesity among female undergraduates.

A study that investigated BMI, WC, and W/H as diagnostic tests for fatness in adolescents found the mean BMI within normal range according to the $\mathrm{WHO}$ classification. ${ }^{25}$ Also the mean $\mathrm{BMI}$ in the present study falls within the normal range and similar results have been reported elsewhere. ${ }^{26}$ The mean WC of the participants found in this study is as well in line with the findings of a recent study. ${ }^{5}$ The normal range of $\mathrm{WC}$ and $\mathrm{W} / \mathrm{H}$ as specified is $79-88 \mathrm{~cm}$ and $0.80-0.84$ respectively.22 The mean $\mathrm{WC}$ and $\mathrm{W} / \mathrm{H}$ of the participants were found to be within the normal range. This is consistent with the findings of previous studies. 5,26 The consistence of our findings with that of Kamadjeu et al may not be surprising because both participants had similar height and WC. ${ }^{5}$ However, this finding differs from that of Onat et al who reported higher values for both WC and W/H in a study of the Turkish adult population. ${ }^{27}$ The difference observed may be as a result of the inclusion criteria; while men and women participated in their study, our study recruited only female undergraduates. In addition, their study subjects were aged 25-74 years whereas the age range of subjects in this study was $18-25$ years with a mean of $22.5 \pm 2.20$ years. Other reasons could involve racial difference, genetic predisposition, and lifestyle of the participants.

In their study of anthropometric measures and prevalence of obesity in the urban adult population of Cameroon, Kamadjeu et al assessed the prevalence of obesity based on BMI, WC, and W/H. ${ }^{5}$ The result showed $19.5 \%$ of the female participants were obese based on BMI measurement. The present study found based on BMI that only $6.3 \%$ of the participants were obese. Huang et al also reported a higher prevalence $(21.0 \%)$ in their study of obesity among the elderly. ${ }^{28}$ The lesser prevalence in our finding may be due to the difference of the study population, environmental factors, and the sample size.

Higher prevalence of $17.6 \%$ and $25.5 \%$ using WC, and W/H measurements respectively were observed in the present study. This agrees with the study of Kamadjeu et al where higher prevalence was found based on WC and W/H measurements. ${ }^{5}$ Also, higher prevalence using WC measurement has been reported in another study. ${ }^{29}$ The higher prevalence obtained may be associated with the excess visceral fat around the abdominal region as well as excess fat deposition around the thigh region, which is often overlooked by most women.

BMI provides a raw measure of obesity across populations; hence, it can be used to estimate the prevalence of obesity and obesityrelated risk factors within a population. ${ }^{3}$ However, other methods that identify people susceptibility to risk of obesity and its related 
problems as a result of abdominal fat accumulation would be useful as complimentary to BMI. This is true, since W/H $>1.0$ in men and $>0.85$ in women indicates abdominal fat accumulation. ${ }^{22}$

Studies have reported A significant correlation between $\mathrm{WC}$ and BMI as well as between $\mathrm{W} / \mathrm{H}$ and $\mathrm{BMI}$ in female populations. 5,20,23,27 Similarly, the present study found a positive and statistically significant relationship between WC and BMI ( $r=$ $0.81 ; p=<0.001)$. Also, W/H was statistically significant and positively correlated with BMI $(r=0.25 ; p=<0.001)$, supporting previously reported results.

\section{Limitations}

This study has limitations as the cross-sectional nature of the study could not permit establishing causal relationships. However, this study is, as far as we can ascertain, the first of its kind in this population. The results buttress the need to incorporate other anthropometric measurements in addition to the traditional BMI measurement of obesity and its related morbidities.

\section{CONCLUSIONS}

There is significant correlation between $\mathrm{WC}, \mathrm{W} / \mathrm{H}$, and $\mathrm{BMI}$, and the prevalence of obesity is relatively low among the study population based on the BMI alone. However, it is high based on the other parameters, especially W/H. Therefore, awareness should be created about the importance of W/H as indicator of obesity among female undergraduates in Nigerian universities and by extension to the overall population of women. Health professionals should consider assessment of WC and W/H of female patients/clients in order to detect obesity early and commence proper intervention. Further studies on a larger sample should include factors such as lifestyle, socioeconomic status, and physical activity among female undergraduates in Nigerian universities. This may add to the available information on the burden of being overweight or classified as being obese as a woman.

\section{Competing Interests}

The authors declare that they have no competing interests be it personal, professional, and/or financial that might have influenced the presentation of the study described in this manuscript.

\section{Acknowledgements}

We would like to express our sincere gratitude to all participants for voluntarily taking part in this study.

\section{REFERENCES}

1. Barness LA, Optiz JM, Gilbert-Barness E: Obesity: genetic, molecular and environmental aspects. Am J Med Genetics 2007, 143A: 3016-3034.

2. Wahab KW, Sani MU, Yusuf BO, Gbadamosi M, Gbadamosi A, Yandutse MI: Prevalence and determinant of obesity- a cross sectional study on an adult northern Nigerian population. Intl Arch Med 2011, 4:10.

3. World Health Organization: Physical Status: The Use of and Interpretation of Anthropometry, WHO technical report series no. 854. Geneva: Report of WHO Expert Committee; 2011:36.

4. Sodjinou R, Agueh V, Fayomi B, Delisle H: Obesity and cardio-metabolic risk factors in urban adults of Benin: Relationship with socio-economic status, urbanization and lifestyle patterns. BMC Public Health 2008, 8:84.

5. Kamadjeu RM, Edwards R, Atanga JS, Kiawi EC, Unwin N, Mbanya JC: Anthropometry measures and prevalence of obesity in the urban adult population of Cameroon: an update from the Cameroon burden of diabetes baseline survey. BMC Public Health 2006, 6:228.

6. Abubakari AR, Lauder W, Agyemang C, Jones M, Kirk A, Bhopal RS: Prevalence and time trends in obesity among adult West African population; a meta-analysis. Obes Rev 2008, 9:297-311.

7. Akpa MR, Mato CN: Obesity in Nigeria: Current trends and management. Nig Med Pract 2008, 54:11-15.

8. Hedley AA, Ogden CL, Johnson CL, Carroll MD, Curtin LR, Flegal KM: Prevalence of overweight and obesity among US children, adolescents, and adults, 1999-2002. JAMA 2004, 201:2847-2850.

9. Sweeting HN: Measurement and definitions of obesity in childhood and adolescence: a field guide for the uninitiated. Nutr $J$ 2007, 6:32.

10. Deurenberg P, Yap M: The assessment of obesity: methods for measuring body fat and global prevalence of obesity. Clin Endocrin Metabol1999, 13:1-11.

11. Kuczmarski RJ, Flegal KM: Criteria for definition of overweight in transition: Background and recommendation for the United States. Am J Clin Nutr 2000, 72:1074-81.

12. Price GM, Uauy R, Breeze E, Bulpitt CJ, Fletcher AE: Weight, shape, and mortality risk in older persons: elevated waist-hip ratio not high body mass index is associated with a greater risk of death. Am J Clin Nutr 2006, 84:449-60. 
13. Visscher TL, Seidell JC, Molarius A, van der Kuip D, Hofman A, Witterman JCM: A comparison of body mass index, waisthip ratio and waist circumference as predictors of all-cause mortality among the elderly: the Rotterdam study. Intl J Obes Metabol Disorders 2001, 25:1730-1735.

14. Rankinen T, Kim SY, Perusse L, Desprs JP, Bouchard C: The prediction of abdominal visceral fat level from body composition and anthropometry: ROC analysis. Intl J Obes 1999, 23:801-809.

15. Vazquez G, Duval S, Jacobs Jr DR, Silventoinen K: Comparison of body mass index, waist circumference and waist/hip ratio in predicting incident diabetes; a meta-analysis. Epidemiol Rev 2007, 29:115-128.

16. Wei M, Gaskill SP, Haffner SM, Stern MP: Waist circumference as the best predictor of noninsulin dependent diabetes mellitus (NIDDM) compared to body mass index, waist/hip ratio and other anthropometric measurements in Mexican Americans- A 7-year prospective study. Obes Res 1997, 5:16-23.

17. de Koninng L, Merchant AT, Pogue J, Anand SS: Waist circumference and waist-to-hip ratio as predictors of cardiovascular events: meta-regression analysis of prospective studies. Eur Heart J 2007, 28:850-856.

18. Chan DC, Watts GF, Barrett PHR, Burke V: Waist circumference, waist hip ratio and body mass index as predictors of adipose tissue compartments in men. Q J Med 2003, 96:441-447.

19. Lean MEJ, Han TS, Marrison CE: Waist circumference as a measure for indicating need for weight management. BMJ 1995, 311:158-161.

20. Wang Z, Hoy WE: Waist circumference, body mass index, hip circumference and waist-to-hip ratio as predictor of cardiovascular disease in Aboriginal people. Eur J Clin Nutr 2004, 58:888-893.

21. Goh VHH, Tain CF, Tong TYY, Mok HPP, Wong MT: Are BMI and other anthropometric measures appropriate as indices for obesity? A study in an Asian population. J Lipid Res 2004, 45:1892-1898.

22. Han TS, Seidell JC, Currall JEP, Morrison CE, Deurenberg P, Lean MEJ: The influences of height and age on waist circumference as an index of adiposity in adults. Intl J Obes 1997, 21:83-89.

23. Odenigbo UM, Odenigbo UC, Oguejiofor OC, Adogu POW: Relationship of waist circumference, waist hip ratio and body mass index as predictors of obesity in adult Nigerians. Pak J Nutr 2011, 10:15-18.

24. World Health Organization: Obesity: Preventing and Managing the Global Epidemic. Geneva: World Health Organization technical report series; 2000:894.

25. Neovius M, Linne Y, Rossner S: BMI, waist circumference and waist-hip-ratio as diagnostic tests for fatness in adolescents. Intl J Obes 2005, 29:163-169.

26. Snehalatha C, Vishwanathan V, Ramachandran A: Cut off values for normal anthropometric variables in Asian Indian adults. Diabetes Care 2003, 26:1380-1384.

27. Onat A, Sansoy V, Uysal O: Waist circumference and waist-to-hip ratio in Turkish adults: interrelation with other risk factors and association with cardiovascular disease. Intl J Cardiol 1999, 70:43-50.

28. Huang K, Lee M, Lee S, Chang Y, Lin Y, Tu S, Pan W: Obesity in elderly and its relationship with cardiovascular risk factors in Taiwan. Obes Res 2005, 13:170-178.

29. Hauner H, Bramlage P, Lösch C, Schunkert H, Wasem J, Jöckel K, Moebus S: Overweight, obesity and high waist circumference. Dtsch Arztebl Int 2008, 105:827-833. 